\title{
Article \\ Improving the assessment of gestational age in a Zimbabwean population
}

\author{
S.A. Feresua, ${ }^{\mathrm{a},}$, B.W. Gillespie ${ }^{\mathrm{b}, \mathrm{c}}$, M.F. Sowers ${ }^{\mathrm{a}}$, T.R.B. Johnson ${ }^{\mathrm{d}}$, K. Welch ${ }^{\mathrm{b}, \mathrm{c}}$, S.D. Harlow ${ }^{\mathrm{a}}$

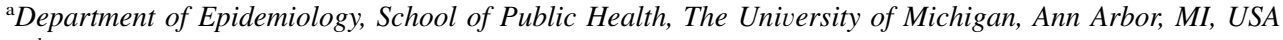 \\ ${ }^{\mathrm{b}}$ Center for Statistical Consultation and Research, The University of Michigan, Ann Arbor, MI, USA \\ ${ }^{\mathrm{c}}$ Department of Biostatistics The University of Michigan, Ann Arbor, MI, USA \\ ${ }^{\mathrm{d} D e p a r t m e n t}$ of Obstetrics and Gynecology, The University of Michigan, Ann Arbor, MI, USA
}

Received 30 January 2002; received in revised form 17 April 2002; accepted 17 April 2002

\begin{abstract}
Objectives: To evaluate the performance and the utility of using birthweight-adjusted scores of Dubowitz and Ballard methods of estimating gestational age in a Zimbabwean population. Method: The Dubowitz and the Ballard methods of estimating gestational age were administered to 364 African newborn infants with a known last menstrual period (LMP) at Harare Maternity Hospital. Results: Both methods were good predictors of gestational age useful in differentiating term from pre-term infants. Our regression line was $Y_{\text {(LMP gestational age })}=23.814+0.301 *$ score for the Dubowitz and $Y_{\text {(LMP gestational age) }}=24.493+0.420 *$ score for the Ballard method. Addition of birthweight to the regression models improved prediction of gestational age; $Y_{\text {(LMP gestational age) }}=23.512+0.219 *$ score $+0.0015 *$ grams for Dubowitz and $Y_{\text {(LMP gestational age) }}=24.002+0.292 *$ score $+0.0016 *$ grams for Ballard method. Conclusions: We recommend the use of our birthweight-adjusted maturity scales; the Dubowitz for studies of prematurity, and the Ballard for routine clinical practice. (c) 2002 International Federation of Gynecology and Obstetrics. Published by Elsevier Science Ireland Ltd. All rights reserved.
\end{abstract}

Keywords: Gestational age; Prematurity; Pre-term; Birthweight; Low birthweight

\section{Introduction}

Estimation of length of gestation is of critical importance in clinical practice to ensure appropriate management of newborns and to distinguish pre-term from term infants. Knowledge of gestational age assists in the identification of infants at

*Corresponding author. Tel.: +1-734-763-5173; fax: +1734-764-3192.

E-mail address: sferesu@umich.edu (S.A. Feresu). risk for morbidity and mortality related to their gestational age and nutritional status. Low birthweight, a common problem in developing countries [1], is due to either short gestation or to being small or light-for-date [1]. Clinical problems encountered with short gestation (pre-term) are different from those experienced in small-for-date infants $[1,2]$. Pre-term infants whose birthweights match their gestational age are at risk of hyaline membrane disease and infection, while small-fordate babies, whether pre-term or term, are more 
liable to suffer from asyphxia and hypoglycemia during the course of labor and immediately postdelivery [3]. In addition, post-maturity problems may arise when mothers are not aware of the first day of their last menstrual period (LMP) and appropriate care is not provided to reduce common complications of post-maturity such as asphyxia or hypoglycemia at birth.

Although LMP is commonly used to estimate gestational age, this approach is dependent on the mother knowing the first day of her last menstrual period. Globally, LMP date is uncertain or unknown in $20 \%$ of pregnant women [4]. In developed countries, women enroll early for prenatal care and advanced technological techniques such as ultrasound can be used to assist ascertainment of gestational age. In most developing countries, however, the majority of women are uncertain about LMP and are more likely to be late attendees for prenatal care [1,5]. Breastfeeding women might not have menstruated before the current pregnancy. Even if ultrasound were readily available, measurements taken late in pregnancy are less reliable in assessing gestational age [6,7].

Alternative, less technologically oriented methods have been developed to assess gestational age based on the developmental status at birth. One method commonly used to estimate gestational age was designed by Dubowitz et al. (1970) [8] and found to be reliable in several African countries $[2,3,9]$. More rapid but equally accurate methods for assessing gestational age were subsequently developed by modifying the Dubowitz method [10-13].

Before using these developmental assessment methods, it is important to norm the scale to the population in which it will be used. In Zimbabwe, an evaluation of the Dubowitz method of assessing gestational age was carried out by Singer et al. [3], but more than two-thirds $(70 \%)$ of their sample had not attended antenatal care and had unknown LMP. The gold standard for gestational age was based on information derived from the midwife asking the mother at birth the month of her last menstrual period, and whether she had menstruated at the beginning, middle or end of that month. More precise gestational age estimates from known LMP are necessary to validate this gestational age assessment method. The validity of the Ballard method has never been evaluated in a Zimbabwean population. This study aimed to validate the Dubowitz and Ballard methods in the Zimbabwean population and to evaluate the utility of incorporating birthweight into the maturity scale.

\section{Methods}

The study was conducted at the Harare Central Hospital Maternity Unit, the largest referral hospital in Zimbabwe between October and December 1999. Harare is composed of the central city and its surrounding suburbs. High-density suburbs are residential areas that in the pre-independence era were called African townships and were areas where all blacks irrespective of class or status resided. Today low to middle income blacks predominately live in these high-density suburbs. The Harare Maternity Hospital serves the black population living in these suburbs, and also serves as a referral center for both surrounding rural hospitals and rural health centers. This hospital was selected as a site for this study because it is the largest hospital in Zimbabwe, with more than 18000 annual deliveries, and it is where Singer et al. [3]. conducted the original validation of the Dubowitz method.

Two research assistants, one a registered nurse and one with a high school equivalent education, were trained over a 1-week period in sample selection techniques, data extraction procedures and infant examination using both the Dubowitz et al. [8] and the revised Ballard et al. [10] methods of assessing gestational age. A pediatrician who used these methods at the hospital for clinical diagnosis of premature babies assisted in training the research team. Intra-observer and inter-observer variations were assessed to evaluate consistency of measurement and a Kappa statistic of 0.8 or better was required prior to beginning enrollment for the study.

To be eligible for this study, women had to have initiated (booked) antenatal care (prenatal care) before 28 weeks of gestation, had regular menstrual cycles, to be aware of their last menstrual period, had a singleton live birth, no medical problems 
during pregnancy, and not used birth control pills within 3 months prior to conception. Very ill babies, stillbirths, malformed babies and babies who died within $24 \mathrm{~h}$ after delivery were excluded because it would be difficult or impossible to administer a neurological assessment. We followed the postulates of Kramer et al. [7] that women booking early for antenatal care have the most accurate recall of LMP. Initially one of our criteria for entry into the study was first antenatal visit at 20-24 weeks, but because in Zimbabwe women generally book late for antenatal care [5,14], we had to relax the criteria to include women who initiated by 28 weeks of gestation. Over a 6 -week period we identified 434 births from a total of 1025 births at Harare Central Hospital Maternity Unit that were eligible for the study. Of the eligible women, six $(1.4 \%)$ refused to participate, 30 (6.9\%) left before they could be examined and 34 (7.8\%) had missing medical records, leaving a total of $364(83.9 \%)$ eligible women who agreed to participate in the study.

Within 2-56 h of delivery, both Dubowitz and Ballard scores were obtained on each eligible women's newborn infant. The majority of the infants $(98.5 \%)$ were examined prior to $30 \mathrm{~h}$ postdelivery with 41 examined between 2 and $6 \mathrm{~h}$ post-delivery, four examined between 30 and $48 \mathrm{~h}$ and two examined more than $48 \mathrm{~h}$ post-delivery. Gestational age was first assessed using the Ballard method and then assessed using the Dubowitz method.

For the Dubowitz method, we evaluated each one of the 11 items used to assess physical maturity, and each of the 10 items used to assess neuromuscular maturity. The neurological and external (physical) criteria sub-scale scores range from 0 to 35 each, giving total possible scores ranging from 0 to 70 [8]. We used the revised version of the Ballard method [10,11]. A total of six items to assess the neuromuscular maturity scale, and six items assess the physical maturity. The range of possible sub-scale scores was -4 to 25 for the neurological criteria, and -8 to 25 for the external criteria, giving total possible scores of -12 to 50 [11].

After completing the infant examination, we measured the mid-arm circumference of both mother and child, maternal weight and height. The LMP date, maternal weight and demographic information recorded at first antenatal care visit and infant birthweight recorded at birth were then abstracted from the medical chart. LMP was used to calculate gestational age and was presumed to be the gold standard for this evaluation. A preterm birth was defined as the birth of an infant at or after 20 weeks and before 37 completed weeks of gestational age.

The study was approved by the University of Michigan Institutional Review Board and the Medical Research Council of Zimbabwe and permission to conduct the study was obtained from the Ministry of Health in Zimbabwe, Harare Central Hospital and from the City Health Department.

\subsection{Statistical analysis}

Descriptive statistics including frequencies, means and standard deviations, were calculated. For each item of the Dubowitz or Ballard method, correlations with gestational age obtained from LMP were estimated, as were correlations with external and neurological sub-scales and total scores. LMP gestational age was plotted against the summary scores. Linear regression models were fitted for total neurological scores, total external criteria scores and total scores and the resultant equations were used to predict gestational age. For each method, we assessed whether prediction of gestational age differed by sex of infant, mother's age, residence, maternal level of education, maternal weight, height, mid-arm circumference, parity, birthweight, and infant's mid-arm circumference using multiple linear regression models. Additional models were then fitted adjusting for infant birthweight. The data were analyzed using SAS version 6.12 and 8.1.

The error of prediction was calculated for the sub-scale and total scores. The beta coefficient estimate from our regression analysis was compared against both the beta coefficient obtained by Dubowitz et al. [8] and that obtained by Singer et al. [3] using a $t$-test. In these calculations, we assumed the value of the coefficient standard error for the two previous Dubowitz studies in Sheffield [8] and Zimbabwe [3] to be equal to that from 
Table 1

Distribution of 364 births by gestational age estimated from last menstrual period and mean birthweight, Harare, Zimbabwe, 1999

\begin{tabular}{|c|c|c|c|c|}
\hline \multicolumn{3}{|c|}{ Gestational age } & \multicolumn{2}{|c|}{ Birthweight (g) } \\
\hline Weeks & $n$ & $\%$ & Mean & Range \\
\hline $24-27$ & 3 & 0.9 & 1081.7 & $700-1795$ \\
\hline 28 & 2 & 0.5 & 1502.5 & $1300-1705$ \\
\hline 29 & 4 & 1.1 & 1540.0 & $1310-1675$ \\
\hline 30 & 4 & 1.1 & 1650.0 & $1410-1940$ \\
\hline 31 & 2 & 0.5 & 1907.5 & $1825-1990$ \\
\hline 32 & 6 & 1.6 & 1881.8 & $1400-2205$ \\
\hline 33 & 7 & 1.9 & 2015.7 & $1545-2440$ \\
\hline 34 & 11 & 3.0 & 2162.5 & $1740-2750$ \\
\hline 35 & 26 & 7.1 & 2369.5 & $1800-3070$ \\
\hline 36 & 22 & 6.0 & 2552.6 & $2150-3020$ \\
\hline 37 & 30 & 8.2 & 2889.0 & $2300-3760$ \\
\hline 38 & 45 & 12.4 & 3048.2 & $2385-4550$ \\
\hline 39 & 61 & 16.8 & 3046.5 & $2365-3970$ \\
\hline 40 & 83 & 22.8 & 3179.0 & $2200-4440$ \\
\hline 41 & 34 & 9.3 & 3358.8 & $2660-4320$ \\
\hline 42 & 18 & 4.9 & 3234.4 & $2690-4045$ \\
\hline $43-45$ & 6 & 1.6 & 3266.7 & $3050-4030$ \\
\hline
\end{tabular}

our current study. We then plotted regression lines from Dubowitz et al. [8], Singer et al. [3] and from our study (0.011). Information on the regression lines were not readily available from the previous Ballard studies [10,11].
To assess which method fared better in the Zimbabwean sample, we compared the correlation coefficients using the individual and total scores, the standard errors of prediction and the time, ease and practicality of performing each procedure. Finally, we used our regression equations to develop new charts for use in the Zimbabwean population. Since birthweight significantly improved the model fit, we calculated birthweight-sensitive maturity scales.

\section{Results}

In this study population of 364 deliveries, the mother's ages ranged from 14 to 44 years with a mean age of 24.5 years. Three-quarters of the mothers $(75.5 \%)$ resided in urban high-density suburbs and very few (14.3\%) came from rural areas. Most women $(83.7 \%)$ had more than primary education. Parity ranged from 0 to 10 with half of the mothers having their first child. Approximately $22.5 \%$ of babies were low birthweight, and $23.9 \%$ were pre-term births.

Mothers weighed between 45 and $98 \mathrm{~kg}$ with a mean of 63.7 (S.D. 9.9) at first antenatal care visit and between 45 and $103 \mathrm{~g}$ with a mean of 63.2 (S.D. 10.4) after delivery. Weight at first antenatal care did not differ from weight after delivery

Table 2

Regression equations for Dubowitz and Ballard Gestational Age Assessment Method: external criteria, neurological criteria and total scores

\begin{tabular}{lllll}
\hline Criteria & $\begin{array}{l}\text { Regression equation } \\
Y=\mathrm{LMP}^{\mathrm{b}} \\
X=\mathrm{score}\end{array}$ & $\begin{array}{l}R \text { - } \\
\text { squared }\end{array}$ & $\begin{array}{l}\text { Standard error of } \\
\hat{B}_{1} \text {, the regression } \\
\text { slope }\end{array}$ & $\begin{array}{l}\text { Standard error of } \\
\text { prediction for a single } \\
\text { observation }^{\mathrm{c}} \\
\text { (weeks) }\end{array}$ \\
\hline $\begin{array}{l}\text { Dubowitz method } \\
\begin{array}{l}\text { Neurological criteria } \\
\text { Physical criteria }\end{array}\end{array}$ & $Y=25.00+0.54 X$ & 0.62 & 0.022 & 1.89 \\
Total scores & $Y=24.75+0.58 X$ & 0.59 & 0.025 & 2.00 \\
$\begin{array}{l}\text { Ballard method } \\
\text { Neurological criteria }\end{array}$ & $Y=23.81+0.30 X$ & 0.66 & 0.011 & 1.82 \\
$\begin{array}{l}\text { Physical criteria } \\
\text { Total scores }\end{array}$ & $Y=25.41+0.74 X$ & 0.55 & & 2.09 \\
\hline
\end{tabular}

${ }^{\text {a }} P$-value for overall model $<0.0001$ for all analyses.

${ }^{\mathrm{b}}$ Standard error of the predicted gestational age (weeks) at mean score.

${ }^{\mathrm{c}}$ Gestational age by last menstrual period. 


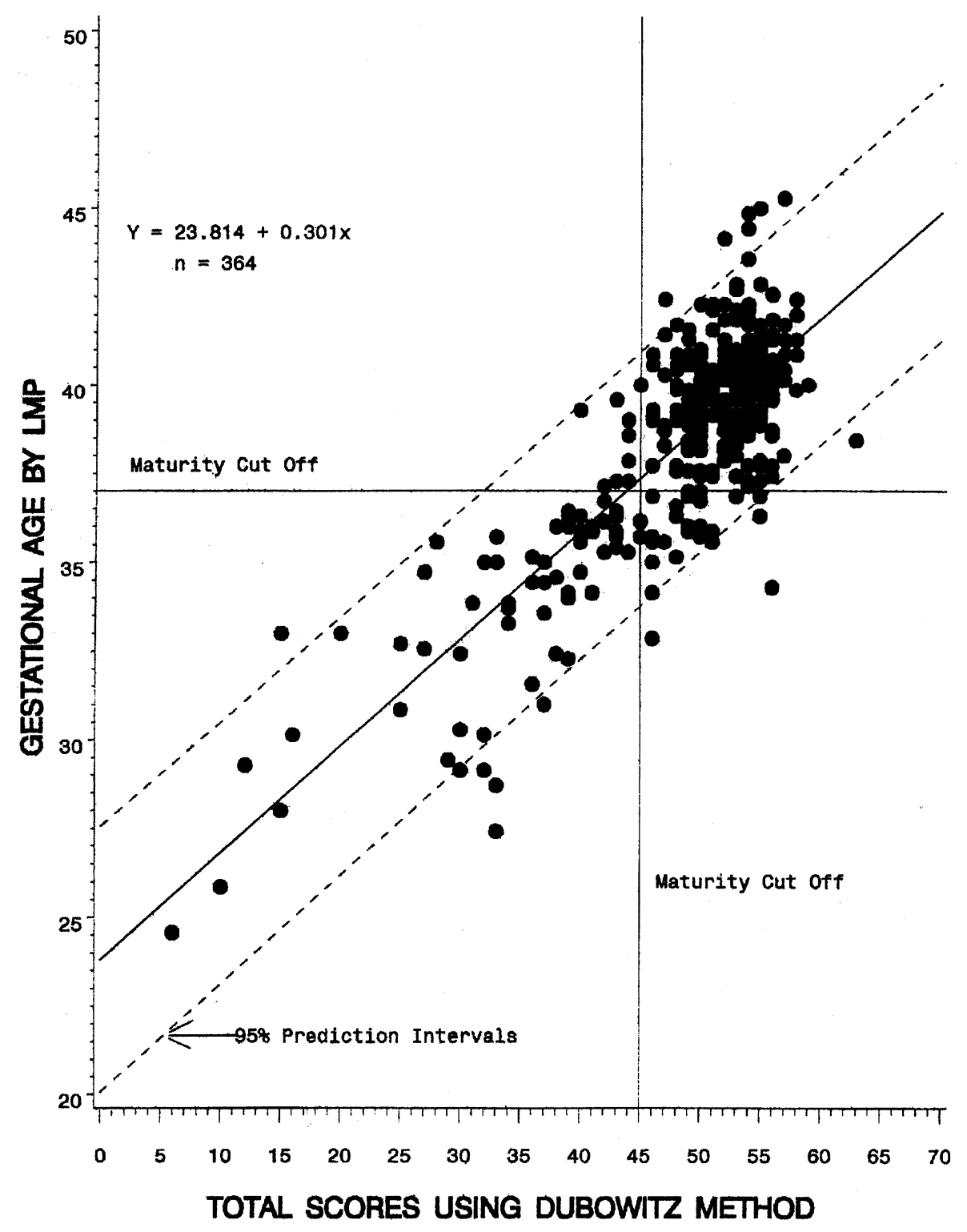

Fig. 1. Distribution of Dubowitz total scores against last menstrual period gestational age in 364 newborn infants at Harare, October to December 1999; includes $95 \%$ confidence intervals.

(paired $t$-test $P=0.4157)$. The mean height was 158.2 centimeters (S.D. 5.9). Women first attended antenatal care between 10.1 and 28 weeks (mean $22.5 \pm 4.2$ weeks). Fundal height measurement at first antenatal care visit ranged between 10 and 28 weeks (mean $22.4 \pm 4.2$ weeks). At birth, the mean gestational age estimated from LMP was 38.5 (S.D. 3.1), and by the physician/midwife was 38.0 (S.D. 2.8).

Table 1 presents the distribution of gestational age estimated from last menstrual period, and the mean birth weights for each stratum. The overall 
Table 3

Comparisons of performance of Dubowitz / Ballard Scores from the current study with original Dubowitz/Ballard and other African studies

\begin{tabular}{llllll}
\hline Study & Country & Year & $\begin{array}{l}\text { Number of } \\
\text { subjects }\end{array}$ & Regression equation & $\begin{array}{l}\text { Correlation } \\
\text { coefficient }^{\mathrm{a}}\end{array}$ \\
\hline $\begin{array}{l}\text { Dubowitz } \\
\text { Dubowitz et al. }\end{array}$ & England & 1970 & 167 & $Y^{\mathrm{b}}=24.59+0.26 X$ & 0.93 \\
Brueton et al. & Nigeria & 1972 & 50 & $Y=26.98+0.23 X$ & 0.74 \\
Singer et al. & Rhodesia & 1973 & 302 & $Y=27.13+0.23 X$ & 0.94 \\
& (Zimbabwe) & & & $Y=24.74+0.27 X$ & 0.90 \\
Raghu et al. & Zambia & 1979 & 160 & $Y=24.00+0.40 X$ & 0.85 \\
Ballard et al. & USA & 1979 & 252 & $Y=23.81+0.30 X$ & 0.81 \\
Current study & Zimbabwe & 1999 & 364 & & \\
Ballard & & & & $Y=24.00+0.40 X^{\mathrm{c}}$ & 0.85 \\
Ballard et al. & USA & 1979 & 224 & $Y=24.00+0.40 X^{\mathrm{c}, \mathrm{d}}$ & 0.97 \\
Ballard et al. & USA & 1991 & 578 & $Y=24.49+0.42 X$ & 0.80 \\
Current study & Zimbabwe & 1999 & 364 & & \\
\hline
\end{tabular}

${ }^{\text {a }}$ Pearson correlation coefficient between gestational age from LMP and total score.

${ }^{\mathrm{b}}$ Gestational age calculated from last menstrual period (LMP).

${ }^{\mathrm{c}}$ We estimated the regression line based on tabulated data of the maturity scale in the Ballard et al. [11] paper.

${ }^{\mathrm{d}}$ The estimated relationship between LMP and Ballard score in the 1979 paper was apparently used without modification in the 1991 paper.

mean birthweight was $2899.2 \mathrm{~g}$ (S.D. 600.8). The mean time taken to conduct a Dubowitz examination was $6.4 \mathrm{~min}$ (range $=2-12 \mathrm{~min}$ ), and a Ballard test was $4.7 \mathrm{~min}$ (range $=2-7 \mathrm{~min}$ ). The mean time difference of $1.7 \mathrm{~min}$ between the methods was statistically significant $(t$-test $P=$ $0.0001)$.

\subsection{Dubowitz method}

Overall the Dubowitz scores were strongly correlated with LMP gestational age, with the Pearson correlation coefficient for the neurological criteria being 0.79 , physical criteria 0.77 and total scores 0.81 . Most individual criteria yielded correlation coefficients above 0.5 except for edema $(r=0.22)$, skin opacity $(r=0.35)$, skin color $(r=0.45)$ and leg recoil $(r=0.47)$ (Appendix A).

Table 2 presents the regression equations for the Dubowitz scores as predictors of gestational age using LMP. Although the neurological and physical criteria for both methods performed well in predicting LMP gestational age, total scores explained more of the variance and had a smaller standard error of prediction of a single score (1.82 weeks). Fig. 1 depicts the distribution of gestational age calculated from LMP by the total score and the maturity cut points for term vs. pre-term births. Few babies lie outside the $95 \%$ prediction intervals.

Table 3 compares the performances of our Dubowitz results with those of the original paper and of other African studies. Although our Dubowitz measures have a somewhat lower correlation with LMP gestational age compared with the original Dubowitz study, they have a higher correlation than that observed in the Nigerian study.[9] Also, our equation is closer to the original Dubowitz equation than was Singer et al. [3]. Fig. 2 compares the original Dubowitz et al. [8] to the Singer et al. [3]. and our regression lines. Our regression line is close to the original Dubowitz below 37 weeks and overestimates gestational age in older babies. The Singer et al. [3] regression line overestimates gestational age up to 42 weeks. Thus, we predict gestational age well for those ages that are important clinically and babies were more frequent. The beta coefficients from these three studies differed significantly from each other using our formula for hypothesis testing $(z=2.37$, $P<0.01$ for Dubowitz et al. [8] and our study; and $z=4.82, P<0.0001$ for Singer et al. and our 


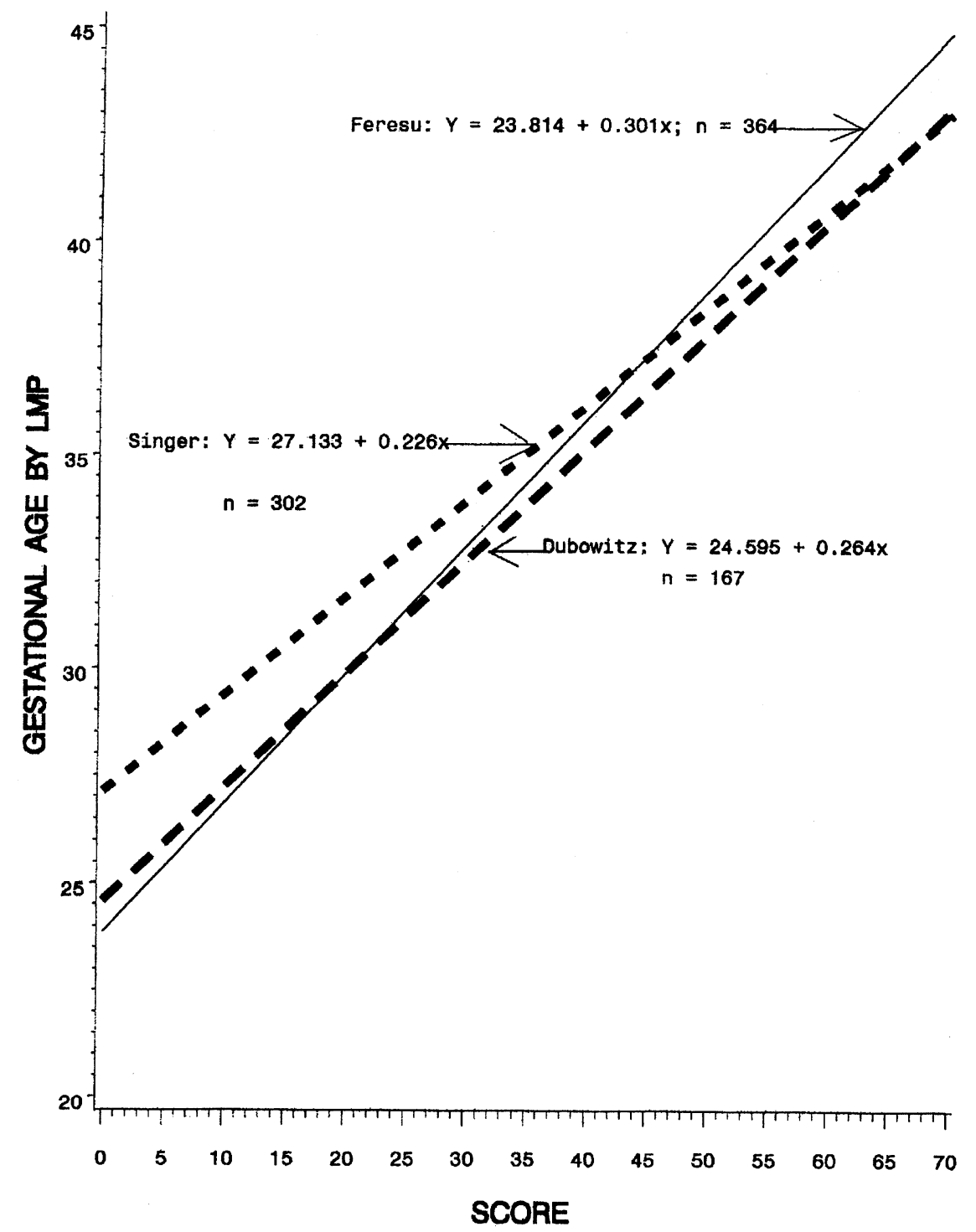

Fig. 2. Comparison of regression lines from Dubowitz (1970), Singer (1973) and Feresu (2001) studies.

study). The Dubowitz et al. [8] and Singer et al. [3] also differed significantly $(z=2.44, P<0.01)$.

Prediction of LMP gestational age did not differ by sex of infant, mother's age, residence, level of education, weight, height, mid-arm circumference, parity and infant's mid-arm circumference. Only birthweight significantly affected prediction of LMP gestational age $(P<0.0001)$. The final model equation including birthweight was $\quad Y_{\text {(LMP gestational age) }}=23.512+0.219 *$ score + $0.0015^{*} \mathrm{~g}$, and it explained $69 \%$ of the variance compared with $66 \%$ of the variance in models without birthweight. We recalculated the maturity scale, taking birthweight into account, thus creating a birthweight-sensitive maturity scale for the Zimbabwean population (Table 4). For each Dubowitz score, we show the estimated gestational age based on the original Dubowitz regression 
Table 4

New Maturity Rating Scales Based on: (1) Dubowitz total scores only; and (2) Dubowitz scores and birthweight; values in bold indicate pre-term births

\begin{tabular}{|c|c|c|c|c|c|c|c|c|c|c|}
\hline \multirow{3}{*}{$\begin{array}{l}\text { Dubowitz } \\
\text { method } \\
\text { total } \\
\text { score } \\
(0-70)\end{array}$} & \multicolumn{10}{|c|}{ Estimated gestational age } \\
\hline & \multirow{2}{*}{$\begin{array}{l}\text { Based on } \\
\text { original } \\
\text { model }(1)^{\text {a }} \\
\text { weeks }\end{array}$} & \multirow{2}{*}{$\begin{array}{l}\text { Based on } \\
\text { current } \\
\text { model }(1)^{\mathrm{b}} \\
\text { weeks }\end{array}$} & \multicolumn{8}{|c|}{$\begin{array}{l}\text { Based on current Dubowitz model adjusted for } \\
\text { birthweight }(2)^{c}\end{array}$} \\
\hline & & & 1000 & 1500 & 2000 & 2500 & 3000 & 3500 & 4000 & 4500 \\
\hline 0 & 24 & 23 & 25 & 25 & 26 & & & & & \\
\hline 5 & 25 & 25 & 26 & 26 & 27 & & & & & \\
\hline 10 & 27 & 26 & 27 & 27 & 28 & & & & & \\
\hline 15 & 28 & 28 & 28 & 29 & 29 & 30 & & & & \\
\hline 20 & 29 & 29 & 29 & 30 & 30 & 31 & 32 & & & \\
\hline 25 & 31 & 31 & 30 & 31 & 32 & 32 & 33 & 34 & & \\
\hline 30 & 32 & 32 & 31 & 32 & 33 & 33 & 34 & 35 & 36 & 36 \\
\hline 35 & 33 & 34 & 32 & 33 & 34 & 34 & 35 & 36 & 37 & 37 \\
\hline 40 & 35 & 35 & 33 & 34 & 35 & 36 & 36 & 37 & 38 & 38 \\
\hline 45 & 36 & 37 & 34 & 35 & 36 & 37 & 37 & 38 & 39 & 40 \\
\hline 50 & 37 & 38 & 36 & 36 & 37 & 38 & 38 & 39 & 40 & 41 \\
\hline 55 & 39 & 40 & & & 38 & 39 & 40 & 40 & 41 & 42 \\
\hline 60 & 40 & 41 & & & & 40 & 41 & 41 & 42 & 43 \\
\hline 65 & 41 & 43 & & & & & 42 & 42 & 43 & 44 \\
\hline 70 & 43 & 44 & & & & & & 44 & 44 & 45 \\
\hline
\end{tabular}

${ }^{\text {a }}$ Calculated using the regression equation: $\mathrm{LMP} \mathrm{GA}=24.595+0.264$ total scores.

${ }^{\mathrm{b}}$ Calculated using the regression equation: $\mathrm{LMP} \mathrm{GA}=23.814+0.301$ total scores.

${ }^{\mathrm{c}}$ Clculated using the regression equation: $\mathrm{LMP} \mathrm{GA}=23.512+0.219$ total scores $+0.0015 \mathrm{~g}$.

model, based on our initial model and also based on our model that included birthweight. Bold type in the table indicates pre-term births. For Dubowitz scores between 35 and 50, classification of preterm infants clearly depends on the method used.

\subsection{Ballard method}

The Ballard sub-scale scores were also highly correlated with LMP gestational age, although the correlations were slightly lower than for the Dubowitz method, being 0.74 for neurological criteria, 0.75 for physical criteria and 0.80 for total scores. Individual criteria correlations were also high, except for breast $(r=0.30)$ and heel to ear $(r=0.42)$ (Appendix B). Table 2 presents the regression equations for the Ballard scores as predictors of gestational age using LMP. Although the neurological and physical criteria performed well in predicting LMP gestational age, total scores again explained more of the variance. The total scores had the smallest standard error of prediction for a single score (1.89 weeks), though the error is slightly higher than 1.82 weeks for the Dubowitz method. Fig. 3 depicts the distribution of gestational age calculated from LMP by the total scores and the cut-offs for term vs. pre-term births. As with the Dubowitz, few babies lie outside the $95 \%$ prediction intervals. Table 3 compares the performances of the Ballard results with those of previous Ballard studies. Our Ballard measure has a relatively lower correlation with LMP gestational age but it compares well with our Dubowitz correlation.

The prediction of LMP gestational age by the Ballard method did not differ by sex of infant, mother's age, residence, level of education, weight, height, mid-arm circumference, parity or infant's mid-arm circumference. Only birthweight significantly affected prediction of LMP gestational age $(P<0.0001)$. The final model equation was $Y_{\text {(LMP gestational age) }}=24.002+0.292 *$ score + $0.0016^{*} \mathrm{~g}$ and explained $67 \%$ of the variance. We recalculated the maturity scale, taking into account 


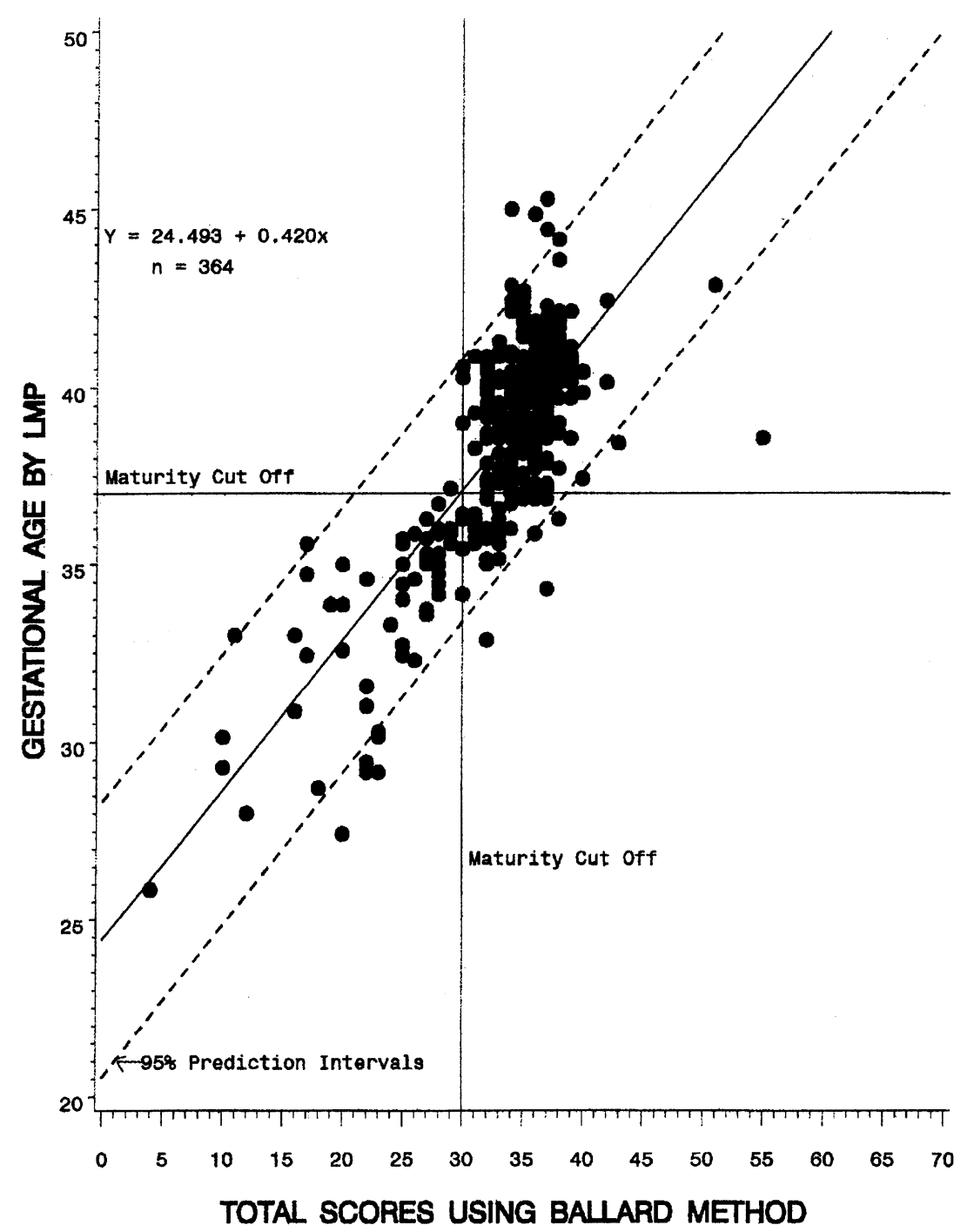

Fig. 3. Distribution of Ballard total scores against last menstrual period gestational age in 364 newborn infants at Harare; October to December 1999; includes $95 \%$ confidence intervals.

birthweight, and created a birthweight-sensitive Ballard maturity scale for the Zimbabwean population (Table 5).

\section{Discussion}

This study evaluated the performance of the Dubowitz and Ballard methods of assessing gestational age in a Zimbabwean population. With a fair degree of accuracy, both methods can reliably be used to differentiate term from pre-term babies in this population. Both methods were comparable in performance with the original methods in previous studies $[8,10,11]$. When comparing the two approaches, the Dubowitz method was a relatively better predictor of LMP gestational age, while the Ballard method took less time, and was easier to administer. Birthweight improved estimation of gestational age for both methods.

Our calculated Dubowitz regression line is comparable with that originally presented by Dubowitz et al. [8] and is relatively better than that calculated 
Table 5

New Maturity Rating Scales based on:(1) Ballard total scores only; and (2) Ballard scores and birthweight; values in bold indicate pre-term births

\begin{tabular}{|c|c|c|c|c|c|c|c|c|c|c|}
\hline \multirow{3}{*}{$\begin{array}{l}\text { Ballard } \\
\text { method } \\
\text { total } \\
\text { score } \\
(-8 \text { to } 48)\end{array}$} & \multicolumn{10}{|c|}{ Estimated gestational age } \\
\hline & \multirow{2}{*}{$\begin{array}{l}\text { Based on } \\
\text { original } \\
\text { model }(1)^{a} \\
\text { weeks }\end{array}$} & \multirow{2}{*}{$\begin{array}{l}\text { Based on } \\
\text { current } \\
\text { model }(1)^{\mathrm{b}} \\
\text { weeks }\end{array}$} & \multicolumn{8}{|c|}{$\begin{array}{l}\text { Based on current Ballard model adjusted for } \\
\text { birthweight }(2)^{\mathrm{c}}\end{array}$} \\
\hline & & & 1000 & 1500 & 2000 & 2500 & 3000 & 3500 & 4000 & 4500 \\
\hline-8 & 20 & 21 & 23 & 24 & 24 & & & & & \\
\hline-4 & 22 & 22 & 24 & 25 & 26 & & & & & \\
\hline 0 & 24 & 24 & 25 & 26 & 27 & & & & & \\
\hline 4 & 25 & 26 & 26 & 27 & 28 & & & & & \\
\hline 8 & 27 & 27 & 28 & 28 & 29 & 30 & & & & \\
\hline 12 & 28 & 29 & 29 & 30 & 30 & 31 & 32 & & & \\
\hline 16 & 30 & 31 & 30 & 31 & 32 & 32 & 33 & 34 & 35 & 36 \\
\hline 20 & 32 & 32 & 31 & 32 & 33 & 33 & 34 & 35 & 36 & 37 \\
\hline 24 & 33 & 34 & 32 & 33 & 34 & 35 & 35 & 36 & 37 & 38 \\
\hline 28 & 35 & 36 & 33 & 34 & 35 & 36 & 37 & 37 & 38 & 39 \\
\hline 32 & 36 & 37 & 35 & 35 & 36 & 37 & 38 & 39 & 39 & 40 \\
\hline 36 & 38 & 39 & 36 & 37 & 37 & 38 & 39 & 40 & 41 & 41 \\
\hline 40 & 40 & 41 & & & 38 & 39 & 40 & 41 & 42 & 43 \\
\hline 44 & 41 & 42 & & & & & & 42 & 43 & 44 \\
\hline 48 & 43 & 44 & & & & & & & 44 & 45 \\
\hline
\end{tabular}

${ }^{\text {a }}$ Calculated using formula LMP GA $=24 .+0.4$ total scores adopted from the Ballard chart (1991).

${ }^{\mathrm{b}}$ Calculated using the regression equation: $\mathrm{LMP} \mathrm{GA}=24.493+0.420$ total scores.

${ }^{\mathrm{c}}$ Calculated using the regression equation: LMP GA $=24.002+0.292$ total scores $+0.0016 \mathrm{~g}$.

by Singer et al. [3] study in predicting LMP gestational age in regions of most clinical importance. A shortcoming of the Singer et al. study [3] is that their sample consisted mostly of mothers who had an unknown LMP. We included only those mothers who had attended prenatal care early and who had known LMP. We also applied stringent inclusion criteria as outlined by other studies [15]. It is therefore not surprising that our regression line is closer to that in the original Dubowitz study. Our slightly lower correlation coefficient could be attributed to factors such as late entry into prenatal care and inability to verify LMP with ultrasound in our population. Our Ballard results also compared favorably with the previous Ballard $[10,11]$ and Dubowitz studies [2,3,8,9]. Given its better performance in the regression models, the Dubowitz method is perhaps more appropriate for use in research studies of prematurity, which demand more precise estimates, while given its relative ease of administration, the Ballard method could be an important tool in routine clinical practice.

For both methods, the standard error of prediction for one single observation was higher than the error reported by the original Dubowitz [8] study, but relatively lower than that reported in Zambia [2] and elsewhere [3,9]. It should be noted that the error of prediction in all these studies is more than one week. Controversy and criticisms of the use of the Dubowitz method to assess gestational age has hinged on the problem of measurement error, especially in very pre-term babies below 34 weeks. The methods tend to overestimate gestational age generally, but especially for pre-term infants [15-17]. As the ability to detect prematurity is a primary reason for doing gestational age assessment, the overestimation of gestational age in pre-term infants is a major concern. We incorporated information on birth weight in an effort to reduce this error. 
Our study found that low birthweight (LBW) significantly decreased prediction of LMP gestational age. Previous studies $[10,16,17]$ have reported that gestational age tends to be overestimated in LBW births, especially for the neurological assessment. Neurological development is accelerated by a high-risk chronically stressed pregnancy such as those complicated by hypertension, preeclampsia or chronic fetal malnutrition. Our study excluded infants from mothers who had medical complications. Some authors [16,17] argue that the prevalence of accelerated neurological maturity may not be sufficient to bias the neurological criteria score. However, within a sample with a high proportion of low birthweight births, this acceleration is likely to be more influential.

Assessing skin color of the African newborn is problematic, especially more than $48 \mathrm{~h}$ post delivery. In this study, $98.5 \%$ of babies were examined by $30 \mathrm{~h}$ post delivery. Other studies have performed examinations at $72 \mathrm{~h}[18], 96 \mathrm{~h}[10,11,15]$ and up to 5 days [8] post-delivery. Nonetheless, we believe these methods are applicable to the African newborn, because prediction of gestational age using these methods has not been shown to differ by racial group $[15,16]$. The key limitation of our study was the practical constraint arising from late entry into prenatal care.

In conclusion, developmental methods for assessment of gestational age, perform well in the Zimbabwean population. Introduction of birthweight into the maturity scale improves assessment of gestational age and corrects for errors caused by low birthweight. We recommend use of our modified birthweight-sensitive Dubowitz assessment for studies of prematurity, and of the modified birthweight-sensitive Ballard method for routine clinical practice. The need remains to evaluate effects of maternal diseases in pregnancy including diabetes, hypertension, anemia, malaria and HIV infection, and of infant morbidity including congenital anomalies and respiratory distress syndrome, on gestational age assessment scores.

\section{Acknowledgments}

Funding for the research was provided by the W.K. Kellogg Foundation.

\section{Appendix A: Dubowitz Assessment method: individual criteria}

Correlations with gestational age obtained from last menstrual period

\begin{tabular}{|c|c|c|c|c|}
\hline Item & Criteria & Score & $\begin{array}{l}\text { Mean } \\
\text { score } \\
\left(\text { S.D. }{ }^{\text {a }}\right)\end{array}$ & $\begin{array}{l}\text { Correlation } \\
\text { coefficient }^{\mathrm{b}}\end{array}$ \\
\hline & \multicolumn{4}{|l|}{$\begin{array}{l}\text { Neurological } \\
\text { criteria }\end{array}$} \\
\hline & Total & 0-35 & $24.9(4.5)$ & 0.79 \\
\hline 1. & Posture & $0-4$ & $3.8(0.55)$ & 0.65 \\
\hline 2. & $\begin{array}{l}\text { Square } \\
\text { window }\end{array}$ & $0-4$ & $2.9(0.43)$ & 0.64 \\
\hline 3. & $\begin{array}{l}\text { Dorsiflexion } \\
\text { of foot }\end{array}$ & $0-4$ & $2.5(0.66)$ & 0.59 \\
\hline 4. & Arm recoil & $0-2$ & $1.9(0.35)$ & 0.55 \\
\hline 5. & Leg recoil & $0-2$ & $1.9(0.33)$ & 0.47 \\
\hline 6. & $\begin{array}{l}\text { Popliteal } \\
\text { angle }\end{array}$ & $0-5$ & $2.5(0.75)$ & 0.63 \\
\hline 7. & Heel to ear & $0-4$ & $2.0(0.68)$ & 0.59 \\
\hline 8. & Scarf sign & $0-3$ & $2.4(0.66)$ & 0.63 \\
\hline 9. & Head lag & $0-3$ & $2.5(0.77)$ & 0.59 \\
\hline \multirow[t]{3}{*}{10.} & $\begin{array}{l}\text { Ventral } \\
\text { suspension }\end{array}$ & $0-4$ & $2.6(0.70)$ & 0.70 \\
\hline & \multicolumn{4}{|l|}{$\begin{array}{l}\text { Physical } \\
\text { criteria }\end{array}$} \\
\hline & Total & 0-35 & $23.9(4.1)$ & 0.77 \\
\hline 11. & Edema & $0-2$ & $2.0(0.12)$ & 0.22 \\
\hline 12. & Skin texture & $0-4$ & $2.6(0.60)$ & 0.57 \\
\hline 13. & Skin color & $0-3$ & $2.3(0.53)$ & 0.45 \\
\hline 14. & Skin opacity & $0-4$ & $2.3(0.55)$ & 0.35 \\
\hline 15. & $\begin{array}{l}\text { Lanugo } \\
\text { Plantar }\end{array}$ & $0-4$ & $2.5(0.63)$ & 0.49 \\
\hline 16. & $\begin{array}{l}\text { creases } \\
\text { Nipple }\end{array}$ & $0-4$ & $2.6(0.73)$ & 0.64 \\
\hline 17. & formation & $0-3$ & $1.8(0.63)$ & 0.55 \\
\hline 18. & Breast size & $0-3$ & $1.8(0.58)$ & 0.57 \\
\hline 19. & Ear form & $0-3$ & $2.3(0.66)$ & 0.57 \\
\hline 20. & $\begin{array}{l}\text { Ear firmness } \\
\text { Genitals }\end{array}$ & $0-3$ & $2.0(0.51)$ & 0.53 \\
\hline 21 & $\begin{array}{l}\text { combined } \\
\text { Genitals- }\end{array}$ & $0-2$ & $1.8(0.42)$ & 0.62 \\
\hline 21a. & $\begin{array}{l}\text { male } \\
\text { Genitals- }\end{array}$ & $0-2$ & $1.9(0.36)$ & 0.60 \\
\hline $21 b$. & female & $0-2$ & $1.8(0.46)$ & 0.63 \\
\hline & Total scores & 0-70 & $48.9(8.4)$ & 0.81 \\
\hline
\end{tabular}

${ }^{\text {aStandard deviation. }}$

${ }^{\mathrm{b}} P$-value $<0.0001$ for all criteria, testing for zero correlation between the Dubowitz criteria and gestational age obtained from last menstrual period. 


\section{Appendix B: Ballard assessment method: indi- vidual criteria}

Correlations with gestational age obtained from last menstrual period

\begin{tabular}{|c|c|c|c|c|}
\hline Item & Criteria & Score & $\begin{array}{l}\text { Mean } \\
\text { score } \\
\text { (S.D.a) }\end{array}$ & $\begin{array}{l}\text { Correlation } \\
\text { coefficient }^{\mathrm{b}}\end{array}$ \\
\hline & $\begin{array}{l}\text { Neurological } \\
\text { criteria }\end{array}$ & & & \\
\hline & Total & -4 to 25 & $17.8(3.1)$ & 0.74 \\
\hline 1. & $\begin{array}{l}\text { Posture } \\
\text { Square }\end{array}$ & 0 to 4 & $3.8(0.54)$ & 0.63 \\
\hline 2. & window & -1 to 4 & $2.9(0.45)$ & 0.57 \\
\hline 3. & $\begin{array}{l}\text { Arm recoil } \\
\text { Popliteal }\end{array}$ & 0 to 4 & $3.8(0.65)$ & 0.58 \\
\hline 4. & angle & -1 to 5 & $2.5(0.72)$ & 0.65 \\
\hline 5. & Heel to ear & -1 to 4 & $2.3(1.15)$ & 0.42 \\
\hline \multirow[t]{3}{*}{6.} & Scarf sign & -1 to 4 & $2.5(0.67)$ & 0.56 \\
\hline & $\begin{array}{l}\text { Physical } \\
\text { criteria }\end{array}$ & & & \\
\hline & Total & -8 to 25 & $15.6(3.2)$ & 0.75 \\
\hline 7. & Skin & -1 to 5 & $2.8(0.62)$ & 0.63 \\
\hline 8. & $\begin{array}{l}\text { Lanugo } \\
\text { Plantar }\end{array}$ & -1 to 4 & $2.7(0.61)$ & 0.55 \\
\hline 9. & creases & -2 to 4 & $2.8(0.62)$ & 0.61 \\
\hline 10. & Breast & -1 to 4 & $2.1(1.28)$ & 0.30 \\
\hline 11. & $\begin{array}{l}\text { Ear } \\
\text { Genitalia }\end{array}$ & -2 to 4 & $2.6(0.63)$ & 0.65 \\
\hline 12. & $\begin{array}{l}\text { combined } \\
\text { Genitalia- }\end{array}$ & -1 to 4 & $2.5(0.73)$ & 0.61 \\
\hline $12 \mathrm{a}$. & $\begin{array}{l}\text { male } \\
\text { Genitalia- }\end{array}$ & -1 to 4 & $2.6(0.74)$ & 0.58 \\
\hline $12 \mathrm{~b}$. & female & $\begin{array}{l}-1 \text { to } 4 \\
\mathbf{- 1 2} \text { to } \\
\mathbf{5 0}\end{array}$ & $2.3(0.69)$ & 0.64 \\
\hline
\end{tabular}

a Standard deviation.

${ }^{\mathrm{b}} P$-value $<0.0001$ for all criteria, testing for zero correlation between the Ballard criteria and gestational age obtained from last menstrual period.

\section{References}

[1] Kramer MS. Determinants of low birth weight: methodological assessment and meta-analysis. Bull WHO 1987;65(5):663-737.

[2] Raghu MB, Patel YS, Gupta K. Estimation of gestational age in Zambian newborn infants. Ann Trop Paediatrics 1981;1:245-247.
[3] Singer B, Blake L, Wolfsdorf J. Estimation of gestational age of African newborn infants by a scoring system. South Afr Med J 1973;47:2074-2077.

[4] Elder MG, Romero R, Lamont RF. 1st ed. Preterm Labor. New York: Churchill Livingstone; 1997. p. 128.

[5] Munjanja S, Lindmark G, Nystrom L. Randomised controlled trial of reduced-visits programme of antenatal care in Harare, Zimbabwe. Lancet 1996;348(92024):364-369.

[6] Henriksen TB, Wilcox AJ, Hedegaard M, Secher NJ. Bias in Studies of preterm and postterm delivery due to ultrasound assessment of gestational age. Epidemiology 1995;6(5):533-537.

[7] Kramer MS, Mclean FH, Boyd ME, Usher RH. The validity of gestational age estimation by menstrual dating in term, preterm, and postterm gestations. J Am Med Assoc 1988;260(22):3306-3308.

[8] Dubowitz LMS, Dubowitz V, Goldberg C. J Pediatrics 1970;77(1):1-10.

[9] Brueton MJ, Palit A, Prosser R. Gestational age assessment in Nigerian newborn infants. Arch Dis Child 1973;48(4):318-320.

[10] Ballard JL, Kazmaier N, Driver M. A simplified score for assessment of fetal maturation of newly born infants. J Pediatrics 1979;95(5 part 1):769-774.

[11] Ballard JL, Khoury JC, Wedig K, Wang L, EilersWalsman BL, Lipp R. New Ballard Score, expanded to include extremely premature infants. J Pediatrics 1991;119(3):417-423.

[12] Capuro H, Konichezky S, Fonseca D, Caldeyro-Barcia R. A simplified method for diagnosis of gestational age in newborn infant. J Pediatrics 1978;93(1):120-122.

[13] Eregie CO. Assessment of gestational age modification of simplified method. Dev Med Child Neurol 1991;33:596-600.

[14] Central Statistical Office (CSO). Zimbabwe Demographic and Health Survey 1994. Columbia, MD: Institute for Resource Dev/Macro System, Inc, 1994. (p. 109).

[15] Shukla H, Atakent YS, Ferrara A, Topsis J, Antoine C. Postnatal overestimation of gestational age in preterm infants. American Journal of Diseases of Children 1987; 141:1106-1107.

[16] Constantine NA, Kraemer HC, Kendall-Tackett KA, Bennett FC, Tyson JE, Gross RT. Use of physical and neurologic observations in assessment of gestational age in low birth weight infants. $\mathrm{J}$ Pediatrics 1987;110(6):921-928.

[17] Spinnato JA, Sibal BM, Shaver DC, Anderson GD. Inaccuracy of Dubowitz gestational age in low birth weight infants. Obstet Gynecol 1984;63(4):491-495.

[18] Sanders M, Allen M, Alexander GR, Yankowitz J, Graeber J, Johnson TRB, et al. Gestational age assessment in preterm neonates weighing less than 1500 grams. Pediatrics 1991;88(3):542-546. 